Viso - Cadernos de estética aplicada

Revista eletrônica de estética

ISSN 1981-4062

No 19, jul-dez/2016

http://www.revistaviso.com.br/
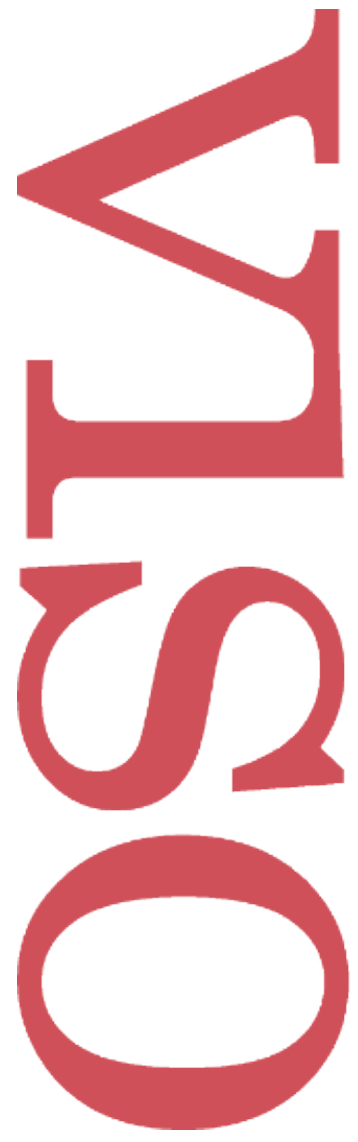

\title{
Por uma arte no mundo da vida Rachel Costa
}

Universidade Estadual de Minas Gerais (UEMG)

Belo Horizonte, Brasil 


\section{RESUMO}

\section{Por uma arte no mundo da vida}

O artigo visa debater a análise colocada por Jacinto Lageira no texto "As razões do agir, contribuição a uma poética da ação". O debate se estabelece no que concerne ao problema da autonomia da arte e suas consequências, tendo em vista a necessidade de pensar possibilidades contemporâneas para a experiência estética que pressuponham o mundo material. Isso é realizado a partir da teoria dos gestos do filósofo Vilém Flusser.

Palavras-chave: gesto - experiência estética - autonomia da arte

\section{ABSTRACT}

\section{For an Art in the Lifeworld}

This article aims to discuss the analysis by Jacinto Lageira in the text "The reasons of action, a contribution for a poetics of action". The debate is established regarding the issue of autonomy of art and its consequences, owing to the need to think contemporary possibilities for aesthetic experience that presuppose the material world. This is accomplished from the theory of gestures of the philosopher Vilém Flusser.

Keywords: gest - aesthetic experience - art autonomy 
COSTA, R. "Por uma arte no mundo da vida". In: Viso: Cadernos de estética aplicada, v. X, n. 19 (jul-dez/2016), pp. 271-278.

DOI: $10.22409 / 1981-4062 / v 19 i / 247$

Aprovado: 29.10.2016. Publicado: 28.12.2016.

(C) 2016 Rachel Costa. Esse documento é distribuído nos termos da licença Creative Commons Atribuição-NãoComercial 4.0 Internacional (CC-BY-NC), que permite, exceto para fins comerciais, copiar e redistribuir o material em qualquer formato ou meio, bem como remixá-lo, transformá-lo ou criar a partir dele, desde que seja dado o devido crédito e indicada a licença sob a qual ele foi originalmente publicado.

Licença: http://creativecommons.org/licenses/by-nc/4.0/deed.pt_BR

Accepted: 29.10.2016. Published: 28.12.2016.

(C) 2016 Rachel Costa. This document is distributed under the terms of a Creative Commons Attribution-NonCommercial 4.0 International license (CC-BY-NC) which allows, except for commercial purposes, to copy and redistribute the material in any medium or format and to remix, transform, and build upon the material, provided the original work is properly cited and states its license.

License: http://creativecommons.org/licenses/by-nc/4.0/ 
Eu gostaria de iniciar o debate com um agradecimento público ao Professor Jacinto Lageira. Claro que ele deve estar imaginando que esse agradecimento se deve ao fato de ele ter me abrigado no departamento no período em que passei na França, durante o meu doutorado, e gostaria de agradecê-lo por isso também. Mas o motivo especial a que me refiro é que ele se dispôs a ler o material que eu tinha pronto e discutir comigo. Nessa discussão ele me disse uma coisa que eu nunca esperava escutar de ninguém: que eu poderia ser mais ousada. Devido a essa contribuição, que considero das mais importantes da minha carreira, me sinto no direito de usar de minha ousadia, a qual foi devidamente cultivada nesses últimos quatro anos, para debater o texto "As razões do agir, contribuição a uma poética da ação".

O problema em questão gira em torno da autonomia da arte e da sua suposta separação do mundo da vida e, consequentemente, das relações que conformam as formas de vida que nele habitam. Nesse sentido, o título do meu ensaio, "Por uma arte no mundo da vida", assim como o texto por mim debatido, propõem analisar não a arte em si em suas variadas tentativas de aproximação do mundo ocorridas no último século, mas as relações estabelecidas entre ela e o público, as quais são trabalhadas dentro do contexto da experiência estética e, consequentemente, da crítica de arte. Sendo assim, a proposta apresentada por Lageira, de compreensão da experiência estética dentro do escopo da teoria da ação, evidencia em que medida é necessário investigar as possibilidades de inter-relação da arte com o mundo. Considero esse o ponto focal onde desaguam as minhas discussões sobre a experiência estética, que têm a crítica como ferramenta de primeira necessidade.

No entanto, Lageira afirma a necessidade de uma abordagem pragmatista, mais especificamente, dentro da teoria da ação, para compreender a experiência estética, ligando-a a um contexto ético no campo da práxis. Ele justifica essa necessidade pela contraposição com o relativismo e o subjetivismo, os quais configuram uma experiência individualizada e multifacetada ao infinito, ou com o idealismo, inviabilizando sua influência na vida prática da sociedade. Todavia, compartilho da desconfiança continental com relação ao pragmatismo que constitui a base de sua abordagem. Não considero ser necessário o pragmatismo para a configuração de uma experiência e uma crítica que sejam contextualizadas, que se situem no universo da práxis humana. Até porque o problema das propostas idealistas é o distanciamento que elas geram entre o mundo da arte e o mundo da vida, sendo esse distanciamento um dos motivadores do surgimento das propostas relativistas.

Além disso, a utilização do pragmatismo para pensar a experiência estética termina por subjugar a estética à ética, visto que o universo da experiência estética é associado a uma normatividade ética, mesmo essa normatividade não sendo a proposição de uma série de regras, como mencionado por Lageira. Acredito que a estética é um campo muito jovem, e ganhou maioridade com grande velocidade. Por isso, retomar a relação de subordinação dela com outros campos da filosofia não me parece a saída necessária 
para a consolidação de uma discussão autônoma do campo. Até porque é justamente na compreensão da estética enquanto filosofia da arte e enquanto crítica de arte, ou seja, em uma relação direta com um objeto que lhe é próprio, que a estética se desvencilha de sua associação milenar com a ética e a epistemologia.

Devido a essas duas questões, penso que minha contribuição para o debate necessitava passar por um diálogo, mas não um diálogo que perpasse a construção da aplicação da teoria da ação pragmatista à estética, mas um diálogo que parte do problema e das consequências geradas pela questão motivadora do texto de Lageira, visto que compartilhamos das mesmas inquietações, somente configuramos caminhos diferentes para abordá-las.

O meu caminho também passa por uma teoria da ação, ou melhor, por uma teoria dos gestos, mas uma teoria da ação inspirada na fenomenologia e no estruturalismo, a teoria de Vilém Flusser. Vilém Flusser, em seu livro Gestos, constrói uma análise da ação humana enquanto proposta de criação de uma Teoria Geral dos Gestos. No primeiro capítulo da edição brasileira do livro, Flusser explica os motivos pelos quais seria necessária a configuração de uma teoria como essa. Segundo ele, a separação entre ciências do espírito e ciências da natureza cria o hiato percebido de forma singular no problema da experiência estética, ou seja, cria o distanciamento que afirmei acima ser um dos motivadores entre arte e práxis. Assim, uma Teoria Geral dos Gestos seria uma possível ligação entre os dois campos separados pela modernidade, nas palavras de Flusser, ela "[...] é competente para movimentos não satisfatoriamente explicáveis por outros tipos de teoria".

Isso significa que a Teoria dos Gestos não pode ser baseada na separação clássica entre objetivo e subjetivo, pois o modelo de explicação objetiva obriga a esquecer a ação e seu universo de particularidades em prol da universalidade, e o modelo de explicação subjetiva cai nos dois problemas acima citados: idealismo e subjetivismo, ou seja, ou a práxis desaparece ou ela se torna a única referência. Justamente por isso compreendo que é possível pensar a relação do indivíduo com a obra de arte, a qual pressupõe uma experiência estética ao mesmo tempo individual e intersubjetiva, que se conforma dentro do mesmo espectro que a proposta pragmatista apresentada por Lageira, mas sem subjugar a estética à ética. A Teoria Geral dos Gestos se configura como alternativa para pensar a experiência estética.

No processo de compreender o que é a Teoria Geral dos Gestos é necessário explicitar que coisa é isso que Flusser está chamando de gesto. Gestos são movimentos deliberados dos corpos ou de instrumentos ligados aos corpos que buscam constituir sentido, os quais não podem ser delimitados por uma explicação causal, mas sim pela busca de seus significados. Os movimentos podem ser passivos ou ativos, ou seja, podem ser ações ou reações. No entanto, apenas as ações são gestos. Gestos expressam e articulam aquilo que apresentam simbolicamente. Isso significa que um 
fenômeno é um todo codificado de sentido. É por isso que todo gesto precisa ser interpretado e não apenas determinado ou explicado. Assim, para Flusser, porque não temos uma teoria interpretativa dos gestos é que estamos limitados a leituras intuitivas e empíricas, as quais desaguam no relativismo.

Isso significa que a metodologia de análise do gesto deve considerar, principalmente, seu caráter de ação. Sendo assim, Flusser propõe o cruzamento entre várias metodologias, para que cada ação específica seja privilegiada em detrimento das várias teorias que a encobrem. O importante é o estabelecimento do critério que melhor se adequa a cada ação, sendo que critérios metodológicos diferentes resultarão em análises também diferentes. Nesse momento o filósofo inclui o pragmatismo entre as metodologias possíveis de serem utilizadas na Teoria do Gesto. No entanto, ele não cabe a uma análise da experiência estética, pois "[....] ordenaria os gestos de acordo com seu efeito sobre o ambiente, [e] implicaria em métodos da sociologia". ${ }^{2}$ Segundo Flusser, a experiência estética precisa ser analisada como pertencente aos gestos comunicativos.

O que falta trazer à tona é a capacidade de engajamento de uma tal teoria, visto que esse se mostra como um dos argumentos centrais da defesa de Lageira para o uso da teoria da ação pragmatista. Em primeiro lugar é preciso especificar o que Flusser chama de engajamento. Engajamento é decisão humana em prol da modificação do mundo, do oferecer-se ao mundo a fim de alterá-lo. Uma tal definição de engajamento conduz automaticamente nosso pensamento para uma abordagem histórica. Todavia, como a teoria dos gestos não é explicável, por não ser objetivável, mas sim interpretável, ela é fundamentalmente anti-historicista. Isso porque a filosofia da história exige que o gesto individual seja expressão de uma liberdade geral, em um "espírito" claramente hegeliano. Já a teoria dos gestos parte do gesto concreto e da análise daquela liberdade específica para sua interpretação.

Flusser afirma que essa liberdade específica tem se tornado cada vez mais consciente de sua característica técnica, ou seja, de sua aplicabilidade na práxis. Ele cita como exemplo dessa tendência os movimentos artísticos, principalmente norte-americanos, das décadas de 1950 e 1960: bodyexpression, happening, livingtheater e actionpanting. Do ponto de vista do engajamento teórico, o filósofo afirma a emergência de várias teorias que têm a práxis como objeto. O problema é ela ser o objeto, pois as explicações objetivas acabam por obscurecer a ação da qual elas partem. Exemplo disso é o próprio pragmatismo. Uma teoria engajada deve tratar do como a liberdade se exprime no gesto, não do fato de ela se exprimir nele. O como exige a consciência do gesto, exige engajamento nele.

Imagino ter deixado claro em que consiste essa Teoria dos Gestos proposta por Flusser e que ela se configura como uma opção para investigar a poética da ação, como mostra o título do texto de Lageira. Agora mostrarei em que medida essa teoria explora aquele 
que é, do meu ponto de vista, o principal ponto da argumentação e da conclusão de seu texto. Para tanto, me valerei do capítulo presente nas versões em alemão e inglês do livro Gestos denominado "Gesten und Stimmung", para o qual utilizarei a tradução "Gesto e sintonia". ${ }^{3}$

Os gestos são proposições estéticas, visto que são climas, são universos de significado, traduzidos em gestos. A vivência desse clima do gesto levanta problemas de ordem ética e epistemológica, ou seja, é parte efetiva do mundo. A delimitação do estético no gesto não passa pela eliminação dos demais aspectos que o constituem, mas pela metodologia utilizada para a análise do mesmo. É nesse ponto que Flusser introduz o conceito de sintonia, o qual ele utiliza para propor uma relação com os gestos que não passa pela explicação causal (característica das perspectivas ética e epistemológica) e que, consequentemente, se aproxima do gesto de uma perspectiva estética.

Assim, a sintonia é a interpretação de gestos como algo que é diferente da razão, ou seja, que expressa um clima artificial transformado em gesto. Assim, a sintonia, na medida em que cria climas artificiais, é um dos modos de o ser humano dar sentido à sua vida, visto que é expressão simbólica junto ao outro, empresta aos climas, sejam eles reais ou imaginários, significação. Isso significa que o conceito de sintonia permite pensar a associação realizada por Lageira entre o prático sensível e o prático moral, na qual a imaginação se apoia e tira consequências de uma experiência estética compreendida como campo de ações, de engajamentos imaginários que podem contribuir para nossa orientação em situação concreta. Em Flusser, esse universo imaginário de engajamento com o mundo se torna possível pela delimitação apenas daquilo que Lageira chama de prático-sensível.

O artificial nos climas apresentados é em primeiro lugar um problema estético. O jogo gestual empresta ao mundo e à vida uma significação estética. Quando queremos criticar a sintonia, precisamos usar critérios estéticos. A escala dos valores que serve de medida não oscila entre verdade e erro ou verdade e mentira, mas deve oscilar entre verdade (autenticidade) e kitsch [...]. Considero essa diferenciação essencial por causa da multiplicidade de significados que a palavra "verdade" carrega em si. Na epistemologia verdade significa adequação com o real; na ética e na política, ser fiel a si mesmo; ao contrário, na arte verdade quer dizer fidelidade ao material com que se lida. ${ }^{4}$

Nesse sentido, um gesto pode ser honesto epistemológica e eticamente, mas desonesto esteticamente, ou seja, não existe uma sintonia do gesto, ele não constrói um clima artificial esteticamente desejável. O contrário também é possível. Isso significa que a escala de valoração estética é diferente das escalas ética e epistemológica, mesmo que o gesto da obra de arte nelas implique. E significa também que há uma escala de valores, ela só não é objetivável.

Sendo assim, o problema relativo à experiência estética abordado por Lageira e mencionado no início do texto está diretamente relacionado à teoria dos gestos. O 
mundo dos gestos é, ao mesmo tempo, codificado por e para nós, ou seja, o universo de significados por ele determinado é criação humana de cultura. A falta de uma teoria da interpretação dos gestos impede a existência de critérios para analisa-los. O que é necessário é uma teoria da interpretação dos gestos, pois sem ela não é possível intersubjetividade na avaliação dos mesmos, o que leva a uma queda no relativismo.

Portanto, a Teoria Geral dos Gestos de Vilém Flusser se configura como uma possibilidade de pensar a experiência estética a partir da relação entre obra de arte e experimentador, abrindo espaço para repensar a crítica e a estética.

* Rachel Costa é professora de estética e filosofia da arte da UEMG.

${ }^{1}$ FLUSSER, V. Gestos. São Paulo: Annablume, 2014, p. 14.

2 Ibidem, p. 23.

${ }^{3}$ Essa é uma das raras vezes em que não há uma tradução em português, nem em inglês, feita pelo próprio Flusser, e o tradutor da versão em inglês cometeu o infortúnio de traduzir Stimmung por "sentimentalização".

${ }^{4}$ FLUSSER, V. Los Gestos: fenomenología e comunicación. Barcelona: Herder, 1994, p. 15. 